\title{
Polycyclic Aromatic Hydrocarbons (PAHs) and their Bioaccessibility in Meat: a Tool for Assessing Human Cancer Risk
}

\author{
Elliyana Nadia Hamidi ${ }^{1}$, Parvaneh Hajeb ${ }^{2}$, Jinap Selamat ${ }^{1}$, Ahmad Faizal Abdull \\ Razis $^{1,3 *}$
}

\begin{abstract}
Polycyclic aromatic hydrocarbons (PAHs) are primarily formed as a result of thermal treatment of food, especially barbecuing or grilling. Contamination by PAHs is due to generation by direct pyrolysis of food nutrients and deposition from smoke produced through incomplete combustion of thermal agents. PAHs are ubiquitous compounds, well-known to be carcinogenic, which can reach the food in different ways. As an important human exposure pathway of contaminants, dietary intake of PAHs is of increasing concern for assessing cancer risk in the human body. In addition, the risks associated with consumption of barbecued meat may increase if consumers use cooking practices that enhance the concentrations of contaminants and their bioaccessibility. Since total PAHs always overestimate the actual amount that is available for absorption by the body, bioaccessibility of PAHs is to be preferred. Bioaccessibility of PAHs in food is the fraction of PAHs mobilized from food matrices during gastrointestinal digestion. An in vitro human digestion model was chosen for assessing the bioaccessibility of PAHs in food as it offers a simple, rapid, low cost alternative to human and animal studies; providing insights which may not be achievable in in vivo studies. Thus, this review aimed not only to provide an overview of general aspects of PAHs such as the formation, carcinogenicity, sources, occurrence, and factors affecting PAH concentrations, but also to enhance understanding of bioaccessibility assessment using an in vitro digestion model.
\end{abstract}

Keywords: Polycyclic aromatic hydrocarbons - barbecued meat - bioaccessibility - in vitro human digestion model

Asian Pac J Cancer Prev, 17 (1), 15-23

\section{Introduction}

Concern over polycyclic aromatic hydrocarbons (PAHs) in foodstuffs was started during the 1960s and 1970s, where two classes of food toxicants producing tumours have been focused i.e. polycyclic aromatic hydrocarbons (PAHs) and N-nitroso compounds (Jägerstad and Skog, 2005). PAHs are referring to a series of organic compound containing two or more fused aromatic rings (Danyi et al., 2009; El-Badry, 2010). PAHs constitute a large class of organic compounds (about 10,000 substances) characterized by a structure made up of carbon and hydrogen atoms (Danyi et al., 2009; Ishizaki et al., 2010; Plaza-Bolańos et al. 2010). PAHs are non-polar compounds with the characteristic of lipophilic, semi-volatile and persistence properties (Plaza-Bolańos et al., 2010; Palm et al., 2011).

PAHs comprise of light PAHs (those containing up to four fused benzene rings) and heavy PAHs (those containing more than four benzene rings). Heavy PAHs are known to be more stable and toxic than light PAHs (Al-
Rashdan et al., 2010; Plaza-Bolańos et al. 2010; Viegas et al., 2012; Abou-Arab et al, 2014). Meanwhile, light PAHs are more volatile, water soluble and less lipophilic compared to heavy PAHs (Farhadian et al., 2010). PAHs containing between two and seven benzene rings are the most PAHs that can be found in the environment. It might be thought that the wide presence of PAHs in the atmosphere is due to the lipophilic characteristics allowing their adsorption onto atmospheric particles and direct deposition in sediments, soils and plants (Danyi et al., 2009).

Importantly, the 16 Environmental Protection Agency (EPA) PAHs have been the main focus of the research community and extensively been monitored as 'priority pollutants' to be controlled in the United States Environmental Protection Agency ( Plaza-Bolańos et al., 2010; Viegas et al., 2012). In 2005, 15 compounds have also been included in the monitoring studies in the European Union (EU) (Plaza-Bolańos et al., 2010).Among these compounds, eight high molecular weight from the US-EPA list i.e. Benzo(a)anthracene, Chrysene, Benzo(b) 
fluoranthene, Benzo(k)fluoranthene, Benzo(a)pyrene, Indeno(1,2,3-cd)pyrene, Benzo(ghi)pyrene, Dibenzo(ah) anthracene were selected to be the most suitable indicators of the occurrence and potential carcinogenic of the entire class of PAHs (Viegas et al., 2012). Table 1 shows the molecular weights and formula structures of the 16 EPA priority PAHs and European Union PAHs of concern in food.

PAHs also can be divided into three groups of

Table 1. Molecular Weights and Formula Structures of the 16 EPA Priority PAHs and European Union PAHs of Concern in Food (Adapted from Purcaro et al., 2013)

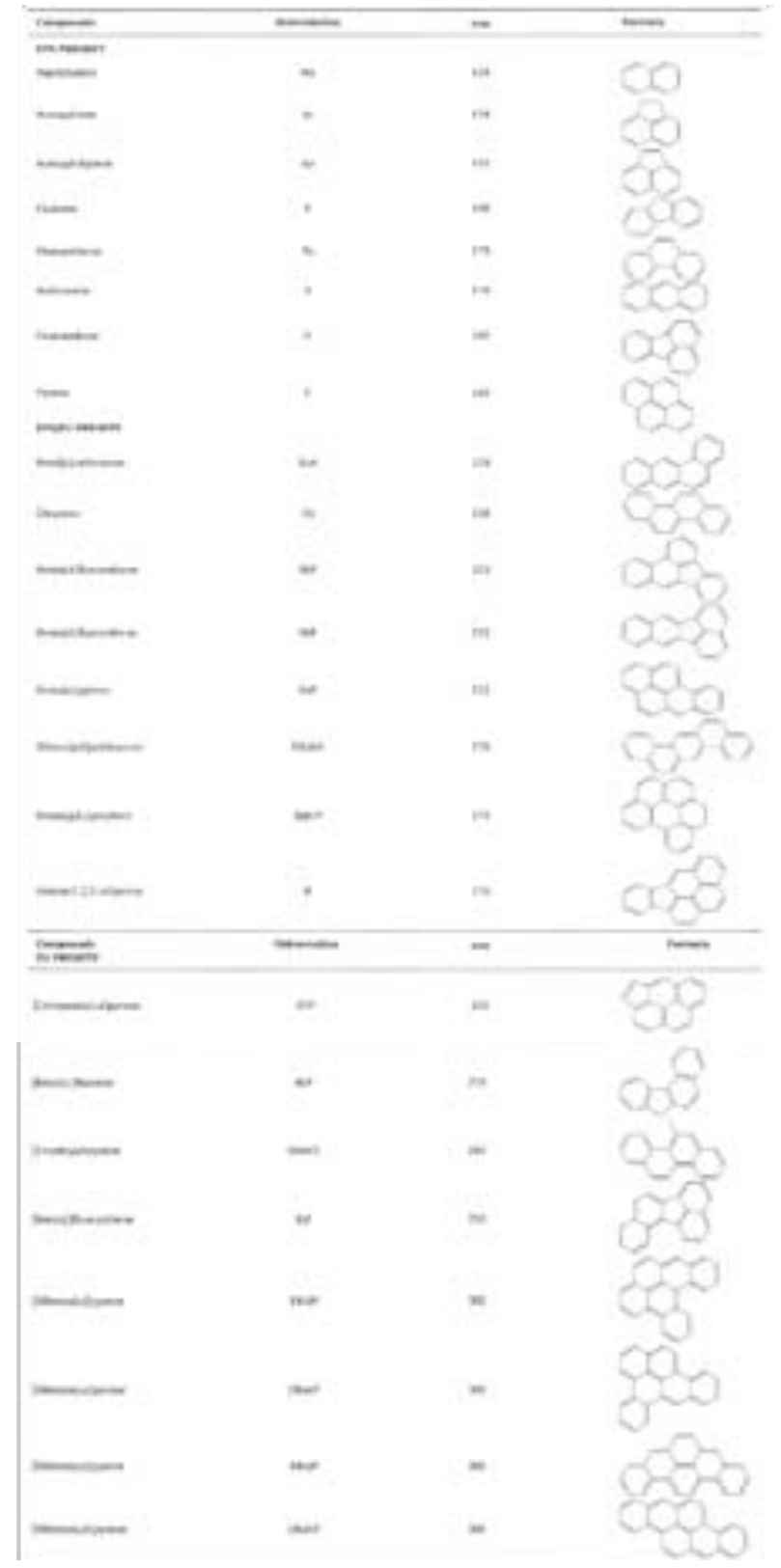

categories based on their molecular weight but having similar environmental fates i.e. low, medium and high molecular weights. These groups of categories are classified according to the number of condensed aromatic rings, their molecular weights and the examples of each category are shown in Table 2.

\section{Formation of PAHs}

Polycyclic aromatic hydrocarbons are produced during variation of combustion and pyrolysis processes from anthropogenic and natural sources including carboncontaining materials such as oil, wood, garbage or coal (Danyi et al., 2009; Silva et al., 2011; Jahurul et al., 2013; Omwukeme et al., 2015). Environmental contamination and food processing i.e. smoking, heating (grilling and/or roasting), drying which allow the direct contact between food and combustion products also can be the significant source for the presence of PAHs in foodstuff (PlazaBolanos et al., 2010; Viegas et al., 2012).

Generally, at least three possible mechanisms exist in the formation of PAHs in grilled/smoked foods even though the exact mechanism is not precisely known (Alomirah et al., 2011). The possible mechanisms are:

First mechanism: The pyrolysis of organic matter such as fat, carbohydrate and protein at temperature above $200^{\circ} \mathrm{C}$ where the favourable condition of PAHs formation is at the temperature ranging from $500-900^{\circ} \mathrm{C}$. The highest concentration of PAHs is shown to arise from pyrolysis of fat.

Second mechanism: The yield of lipids dripping in direct contact over the flame at intense heat. This condition is suitable in the formation of volatile PAHs, which then deposited on the meat surface as the smoke rises.

Third mechanism: The incomplete combustion of charcoal which can generate PAHs that in turn is adhered to the surface of the food.

PAHs were produced in the processed and cooked food as a consequence of organic matter combustion during cooking and smoking process and also direct deposition of PAHs from produced smoke through incomplete combustion of different thermal agents (Farhadian et al., 2011; 2012). Incomplete combustion is, by itself, responsible for the formation of PAHs contaminating grilled food. The heat on the surface of the muscle food generates these contaminants by direct pyrolysis of food nutrients. Additionally, the natural meat and fish juices which are released during the grilling and fall from the muscle food into the charcoal can suffer pyrolysis and lead to formation of PAHs, which being dragged by the smoke and deposited on the surface of the food. Fat dripping from

Table 2. Categories of PAHs Based on their Molecular Weight (Adapted from Palm et al., 2011)

\begin{tabular}{llcl}
\hline Categories & $\begin{array}{c}\text { Low molecular } \\
\text { weight (LMW) }\end{array}$ & $\begin{array}{c}\text { Medium molecular weight } \\
(\mathrm{MMW})\end{array}$ & $\begin{array}{c}\text { High molecular } \\
\text { weight (HMW) }\end{array}$ \\
\hline Aromatic rings & two- and three rings & four- rings & five- to seven- rings \\
Molecular weight & $152 \mathrm{~g} / \mathrm{mol}-178 \mathrm{~g} / \mathrm{mol}$ & $202 \mathrm{~g} / \mathrm{mol}$ & $228 \mathrm{~g} / \mathrm{mol}-278 \mathrm{~g} / \mathrm{mol}$ \\
Example & i) phenanthrene & i) fluoranthene & i) benzo(a)pyrene \\
& & ii) pyrene & ii) dibenzo(a,h)anthracene \\
& & iii) indeno(1,2,3-cd)pyrene & \\
\hline
\end{tabular}


the grilling in wood charcoal lead to flame formation, thus increasing the release of smoke that carries PAHs and the temperature near the surface during the flashing (Viegas et al., 2012).

\section{Human Exposure to PAHs}

PAHs can reach to the human body by different modes of exposure. The routes of exposure to PAHs can be through inhalation, skin contact as well as through consumption of contaminated food. The ways that human can be exposed to PAHs are presented in Table 3 .

Among these routes, consumption of contaminated food has been identified as a principal route of human exposure to PAHs as it contributes about 88 to $98 \%$ of such contamination (Plaza-Bolanos et al., 2010; Silva et al., 2011; Omwukeme et al., 2015). Based on Al-Rashdan et al. (2010), exposure of PAHs to human does not present individually, but in complex mixtures of PAHs. In fact, PAHs usually present in a mixture of two or more of these compounds, for instance soot, coal tar and diesel fuel (Knightes and Peters, 2006; Marti-Cid et al., 2008).

PAHs may present a health risk to human as PAHs become activated in liver, intestine and other extra hepatic tissues to reactive metabolites that interfere with target organ function, leading to fatal and cause toxicity (Marques et al., 2011). The factors which contribute to absorption of dietary PAHs can be the size of PAHs, lipophilicity of PAHs compound and the lipid content of food (Marques et al., 2011). After being absorbed, PAHs are distributed by blood to several tissues, especially those with a high fat content, and some are metabolized to DNA-active mutagen or genotoxic carcinogenic compounds (diol epoxides) (Marques et al., 2011). It has been reported that absorption of $14 \mathrm{C}-\mathrm{BaP}$ in Wistar rats was increased with the diet containing high lipid contents and was restrained when feeding high-fibre foods (Purcaro et al., 2013).

Many case-control studies have been extensively described on exposure of human workers to PAHs through their occupation as well as through dietary exposure (Anderson et al., 2002; Jagerstad and Skog, 2005; Jarvis et al., 2014). From the case control studies, occupational exposure associated with human cancers were observed at various sites including bladder, esophagus/stomach, respiratory system, larynx, skin and kidney, and primarily in the lungs site (Jarvis et al., 2014). In that case, several factors have been linked to the exposure of PAHs and cancer such as smoking, cooking, dietary intake as well as wood burning. Tobacco smoking is known to be the larger contributor to lung cancer incidence in humans, which account approximately $90 \%$ of all lung incidences and 1.2 million deaths per year worldwide (IARC, 2004; Jarvis et al., 2014).

In addition, smoking has also been identified as a cause of cancer in a number of other human organ sites. The interaction between tobacco smoking, B(a)P and DNA damage have been reviewed recently as $\mathrm{B}(\mathrm{a}) \mathrm{P}$ was one of the first carcinogenic compounds detected in tobacco smoke (Jarvis et al., 2014). Besides, from the case study by Jagerstad and Skog (2005), the exposure of PAHs from tobacco smoking and the workplace indicated the target organs include lung, breast and gastrointestinal tracts. In addition, consumption of grilled/barbecued red meat was associated with pancreatic and stomach cancer (Anderson et al., 2002).

On the other hand, the primary route of non-smokers to be exposed to PAHs is mostly through dietary exposure to complex PAH mixtures which can also give significant risk for human cancer development such as colorectal, pancreatic and prostate cancer. Apart of food

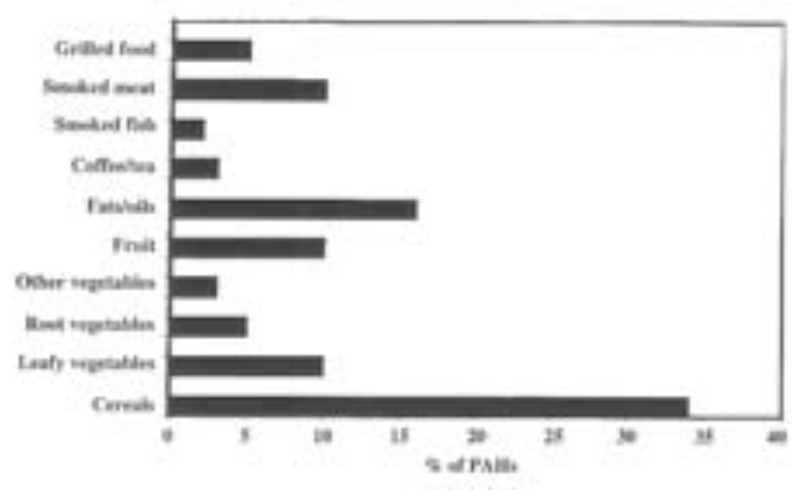

Figure 1. Estimated Contributions (\%) of Nine PAHs (fluoranthene, pyrene, benzo (a) anthracene, chrysene, benzo(b)fluoranthene, benzo (j) fluoranthene/benzo(k) fluoranthene, benzo(e)pyrene, benzo(a)pyrene and indeno(1,2,3-cd)pyrene) in Various Food Groups of Swedish diet (Adapted from Jägersted et al., 2005)

\section{Table 3. Routes of Human Exposure to PAHs}

\begin{tabular}{|c|c|c|}
\hline Route of exposure & Occurrences & References \\
\hline Inhalation & $\begin{array}{l}\text { Inhalation of tobacco smoke, wood smoke and ambient air } \\
\text { Inhalation of engine exhaust } \\
\text { People working in industries such as mining, } \\
\text { oil refining and metal working }\end{array}$ & $\begin{array}{l}\text { Abou-Arab et al. (2014) } \\
\text { Jarvis et al. (2014) } \\
\text { Silva et al. (2011) } \\
\text { Public Health England (2008) } \\
\text { Falco et al. (2003) }\end{array}$ \\
\hline Skin contact & $\begin{array}{l}\text { Breathing in or touching PAHs for a long time were } \\
\text { suggested to cause lung or skin cancer }\end{array}$ & $\begin{array}{l}\text { Jarvis et al. (2014) } \\
\text { Silva et al. (2011) } \\
\text { Public Health England (2008) } \\
\text { Falco et al. (2003) }\end{array}$ \\
\hline $\begin{array}{l}\text { Consumption of } \\
\text { contaminated food }\end{array}$ & $\begin{array}{l}\text { Eating food containing PAHs } \\
\text { Fruits and vegetables grown in contaminated soil } \\
\text { Processed food (charbroiling and grilling at high temperatures) }\end{array}$ & $\begin{array}{l}\text { Abou-Arab et al. (2014) } \\
\text { Jarvis et al. (2014) } \\
\text { Silva et al. (2011) } \\
\text { Public Health England (2008) }\end{array}$ \\
\hline
\end{tabular}


Table 4. IARC Classification of PAHs according to Possibility to be Carcinogenic to Human (Adapted from IARC, 2010)

\begin{tabular}{lcc}
\hline $\begin{array}{l}\text { Group 1 } \\
\text { (carcinogenic to human) }\end{array}$ & $\begin{array}{c}\text { Group 2A } \\
\text { (probably carcinogenic to human) }\end{array}$ & $\begin{array}{c}\text { Group 3 } \\
\text { (possibly carcinogenic to human) }\end{array}$ \\
\hline Benzo(a)pyrene & Benzo(a)anthracene & Benzo(a)anthracene \\
& Dibenzo(a,h)anthracene & Benzo(k)fluoranthene \\
Dibenzo(a,l)pyrene & Benzo(b)fluoranthene \\
& Benzo(j)fluoranthene \\
& Dibenzo(a,h)pyrene \\
& Dibenzo(a,i)pyrene \\
& 5-methylchrysene \\
& Indeno(1,2,3-cd)pyrene \\
\hline
\end{tabular}

Table 5. Sources of PAHs Contamination in Food Products

\begin{tabular}{|c|c|c|}
\hline Sources & Occurrences & References \\
\hline 1. Soils, air and water: & $\begin{array}{l}\text { PAHs can accumulate on the waxy surface of many vegetables and fruits } \\
\text { because of particulate deposition on vegetables and fruits resulting from air } \\
\text { pollution. }\end{array}$ & Jahurul et al. (2013) \\
\hline soil (by deposition) & $\begin{array}{l}\text { Seafood and fish can be exposed to PAHs that present in water and sedi- } \\
\text { ments. (e.g: bivalve mollusks species contaminated with a wide range of } \\
\text { PAHs due to the oil spills present in the sea. }\end{array}$ & Chung et al. (2011) \\
\hline air (by transfer) & & Farhadian et al. (2011) \\
\hline water (by deposition and transfer) & & Plaza-Bolańos et al. (2010) \\
\hline 2. Mode of cooking: & $\begin{array}{l}\text { Smoking, heating (grilling, roasting and drying) permit the direct contact } \\
\text { between food and combustion products (i.e. important sources of PAHs } \\
\text { contamination for seeds, edible oils, meat and dairy products). }\end{array}$ & Chung et al. (2011) \\
\hline smoke curing & & Plaza-Bolańos et al. (2010) \\
\hline \multicolumn{3}{|l|}{ broiling } \\
\hline \multicolumn{3}{|l|}{ roasting } \\
\hline \multicolumn{3}{|l|}{ grilling over open fires or charcoal } \\
\hline 3. Food additives: & $\begin{array}{l}\text { Smoke flavouring products (SFP), which are utilized to improve..organo- } \\
\text { leptic characteristics produced from smoke condensates, which can be a } \\
\text { significant source of PAHs in food. }\end{array}$ & Chung et al. (2011) \\
\hline smoking flavour agents & $\begin{array}{l}\text { Recycled polyethylene film in oil..packaging..could contaminate vegetable } \\
\text { oils with PAHs by rediffusion. }\end{array}$ & Plaza-Bolańos et al. (2010) \\
\hline \multicolumn{3}{|l|}{ lubricants } \\
\hline \multicolumn{3}{|l|}{ solvents } \\
\hline \multicolumn{3}{|l|}{ propellents } \\
\hline \multicolumn{3}{|l|}{ glazing agents } \\
\hline \multicolumn{3}{|l|}{ protective coatings } \\
\hline \multicolumn{3}{|l|}{ 4. Traffic } \\
\hline & $\begin{array}{l}\text { Exposure to PAHs and nitro-PAHs (derivatives of PAHs) when roads are } \\
\text { nearby to crops or livestock. }\end{array}$ & Plaza-Bolańos et al. (2010) \\
\hline
\end{tabular}

consumption, cooking also has been linked to human cancer development as reported in China. High levels exposure of unvented smoke from indoor cooking was resulted in unusually high levels of lung cancer mortality rates among women (Alomirah et al., 2011; Jahurul et al., 2013; Jarvis et al., 2014).

\section{Carcinogenicity of PAHs}

The presence of PAHs in food is of considerable interest since some of them has the ability to cause cancer. Concerning PAHs, these cooked food toxicants have been evaluated by the International Agency for Research on Cancer (IARC, 2010), which has come out with the conclusion and categorized the toxicant into few groups; Group 1 (carcinogenic to human), Group 2A (probably carcinogenic to human), Group 2B (possibly carcinogenic to human) and Group 3 (unclassified as carcinogenic to human). The examples of PAHs included in these groups can be seen as tabulated in Table 4 .

According to the group listed above, benzo(a)pyrene (BaP) has been a subject of concern where in 1987, IARC has classified $\mathrm{BaP}$ as the most probable human carcinogen. Thus, the determination of $\mathrm{BaP}$ has been widely used as an indicator for the carcinogenic of PAHs present in environmental since the profile of the measured PAHs in various foodstuffs do not seems to differ very much (Plaza-Bolańos et al., 2010; Purcaro et al., 2013). The 
Joint FAO/WHO Expert Committee on Food Additives (JECFA) has stated the amount of BaP in foods should not exceed $10 \mathrm{ppb}$ (Chung et al., 2011).

PAHs are regarded as potential genotoxic and carcinogenic to humans. After metabolic activation in mammalian cells to diol-epoxides, PAHs will bind covalently to cellular macromolecules, including DNA, thereby causing errors in DNA replication and mutations that initiate the carcinogenic process (Reinik et al., 2007; Farhadian et al., 2010; 2012). Exposure to high levels of dietary and environmental PAHs has been associated with numbers of incidences for instance esophageal and colorectal cancers development as well as endocrine disruption-related infertility (Ramesh et al., 2004). The PAHs content in smoked meat and fish has been extensively reported as an increased risk of stomach cancer observed in certain population who consumed the food at high frequency (Viegas et al., 2012).

Moreover, a number of epidemiological studies also evaluated the relationship between preference for welldone cooked meat with risk of cancer (Marchand et al., 2002; Jinap et al., 2013). Several cases have been shown to give positive correlations between well-done cooked meat intake with cancer incidences especially for colorectal and breast cancer (Sinha et al., 2000; 2001; Afzaninawati et al., 2013; Jinap et al., 2013).

\section{Sources of PAHs as Food Contaminant}

PAHs can contaminate foodstuffs by several ways, either via direct or indirect contact with smoke (AlRashdan et al., 2010). Direct contact with smoke occurs when involving no obstacles between the foodstuffs and smoke; while, indirect contact with smoke is a placing of an obstacle, i.e. a stainless steel plate above the smoke generator (Gomes et al., 2009). Direct exposure of meat products to smoke contributed to higher levels of PAHs compared to indirect methods due to partially elimination of PAHs by condensation in tars (Šimko, 2002).

Interestingly, PAHs can be detected in wide range of food products such as dairy products, vegetables, fruits, oils, coffee, tea, cereals and smoked meat (Chung et al., 2011; Jahurul et al., 2013). Figure 1 shows the estimated contribution (\%) of commonly nine PAHs reported in food within various food groups in Swedish diet including grilled food, smoked meat, smoked fish, coffee/tea, fats/oils, fruit, other vegetables, root vegetables, leafy vegetables and cereals. Contamination of these food products arises generally emanate from various sources. Foods can be contaminated by environmental PAHs that are present in the soil (by deposition); air (by transfer); water (by deposition and transfer); mode of cooking i.e. smoke curing, broiling, roasting, grilling over open fires or charcoal; through adding food additives to foods i.e. smoking flavour agents, lubricants, solvents, propellants, glazing agents, protective coatings as well as by traffic (Plaza-Bolańos et al. 2010; Chung et al. 2011; Farhadian et al. 2011; Jahurul et al. 2013). Table 5 summarizes the sources of PAHs contamination in food products.

\section{PAHs in Processed and Cooked Food}

As far as toxic PAHs is concerned, several studies have been carried out evaluating PAHs in processed and cooked food, especially in grilled and smoked foods (Reinik et al., 2007; Akpambanga et al., 2009; Perello et al., 2009; Farhadian et al., 2010; 2011). Recently, Omwukeme et al. (2015) reported that PAHs concentration was detected as high as $200 \mu \mathrm{g} / \mathrm{kg}$ of individual PAH in smoked fish and meat. Jahurul et al. (2013) has also measured the sum of three PAHs (fluoranthene, benzo(b)fluoranthene, benzo(a) pyrene) and reported that the level of PAHs in beef satay (66.28 ng/g), chicken satay (42.31 ng/g), charcoal grilled fish (40.69 ng/g), mutton satay $(30.76 \mathrm{ng} / \mathrm{g})$ and chicken barbecued (17.86 ng/g).

In other study by Farhadian et al. (2010), PAHs appear in grilled meat or fish at variable rates of 0 to $130 \mathrm{ng} / \mathrm{g}$ with the concentration of benzo(a)pyrene $(\mathrm{BaP})$ were in the range of 0.2 to $50 \mathrm{ng} / \mathrm{g}$. Some of the highest concentration of PAHs was also found in the food cooked over open flames such as barbecued meat with total PAHs detected to be up to $164 \mathrm{ppb}$ and $\mathrm{B}(\mathrm{a}) \mathrm{P}$ at concentration as high as $30 \mathrm{ppb}$ (Farhadian et al., 2010). In Estonia, high BaP levels were found in homemade ham, smoked meat, smoked chicken and smoked sausages with concentration of 30.6, $31.2,15.0$ and $20.0 \mu \mathrm{g} / \mathrm{kg}$, respectively (Reinik et al., 2007). In grilled chicken breast on charcoal, fluoranthene and benzo(a)pyrene were found at concentration of 0.57 $\mathrm{ng} / \mathrm{g}$ and $0.15 \mathrm{ng} / \mathrm{g}$, respectively (Janoszka et al., 2004).

Naphthalene, phenanthrene, fluoranthene and pyrene were reported to be the predominant PAHs in food by Farhadian et al. (2011); while dibenzo(ah)anthracene, benzo(b)fluoranthene and benzo(k)fluoranthene were found to be low in concentration in food screened by Martorell et al. (2010). Recently, the levels of PAHs were determined in a few Malaysian foods. Table 6 shows the level of PAHs in different Malaysian grilled meat dishes among three different cooking methods i.e. charcoal grilling, gas grilling and oven grilling.

In reference to Table 6 , beef satay grilled by charcoal grilling showed the highest level of PAHs in the range of 81.0 to $132 \mathrm{ng} / \mathrm{g}$. In turn, the lowest level of PAHs was found in grilled chicken by oven grilling (3.51-7.14 ng/g). The levels of PAHs in meat products can be minimized through alternative cooking methods for instance broiling, baking, stewing as well as cooking at lower temperature and shorter time (Anderson et al., 2002). As charcoal grilling can be applied to foods both as direct or indirect way, no carcinogenic PAHs will be detected in the grilled products if dripping of melted fat onto the heat source is prevented. Therefore, avoiding direct contact of meat with the cooking flame or grilling at low temperature can reduce the formation of PAHs during charcoal grilling (Farhadian et al., 2012).

Furthermore, meat and other meat products, especially when they are in well-done cooked situation, may induce the production of chemical carcinogens exposure, like PAHs and other pyrolysis products which vary accordingly to cooking processes, duration of cooking and type of meat (Farhadian et al., 2012). Similar findings were also reported by Jahurul et al. (2013), showing that the highest 
Table 6. The Level of PAHs in Different Grilled Meat Dishes among three Different Cooking Methods (Adapted from Farhadian et al., 2010)

\begin{tabular}{llc}
\hline Samples & Cooking method & $\begin{array}{c}\text { Sum of three } \\
\text { PAHs (ng/g)* }\end{array}$ \\
\hline Beef satay & Charcoal grilled & $81.0-132$ \\
Ayam bakar & Charcoal grilled & $28.9-51.1$ \\
Chicken satay & Charcoal grilled & $14.3-37.6$ \\
Ikan bakar & Charcoal grilled & $9.36-15.0$ \\
Beef kebab & Gas grilled & $9.36-15.0$ \\
Chicken kebab & Gas grilled & $8.23-20.4$ \\
Grilled chicken & Gas grilled & $4.63-12.4$ \\
Tandoori (chicken) & Oven grilled & $4.65-9.66$ \\
Oven grilled chicken & Oven grilled & $3.51-7.14$ \\
\hline$*$ [fluca
\end{tabular}

* [fluoranthene, benzo(b)fluoranthene, benzo(a)pyrene]

level of benzof(a)pyrene was found in very well-done grilled/barbecued beef satay, charcoal grilled fish and very well-done chicken satay.

Significance numbers of PAHs normally occur at the surface of the product; however, diffusion into the inner parts can take place during storage (Gomes et al., 2009; Marques et al., 2011). Almost 99\% of all PAHs were detected in the outer layer of dry sausage as reported from the previous studies on the migration of PAHs compound into smoked meat products (Jira et al, 2006; Roseiro et al., 2008; Gomes et al., 2009; Marques et al., 2011). The maximum concentration of PAHs in smoked products is attained immediately after the smoking period was completed, decreasing afterwards due to decomposition, triggered by light and interaction with other compounds (Marques et al., 2011; Palm et al., 2011). However, PAHs concentration from the inner parts of the food product is usually stable due to the protection from light and oxygen (Šimko, 2002; Marques et al., 2011).

\section{Factors Affecting PAHs Concentration in Grilled Meat}

Concentration of PAHs in grilled meat depends on several factors. The most important factors contribute to the concentration of PAHs are types of meat, fat content of the food, cooking methods, cooking temperature, cooking duration/level of doneness, type of fuel used/type of heat sources and proximity/direct contact with heat source. The influence of these factors has been subjected to several studies as following:

\section{i) Type of meat}

Type of meat such as chicken and beef meat can be different in terms of fat content, marbling as well as myoglobin content which may influence the level of PAHs released (Kulp et al., 2003). Some studies have reported that the concentration of PAHs is higher in grilled meat as compared to grilled chicken samples (Alomirah et al., 2011).

\section{ii) Fat content of the food}

Fat content of food can contribute to the generation of PAHs through either thermal degradation or polymerization as well as through different thermal processes which affect the formation of PAHs quantitatively (Palm et al., 2011). Based on Purcaro et al. (2013), fat is the major precursor of PAHs formation where the amount of fat content in the processed food affects the level of PAHs. Grilling meat with appreciable fat content would contribute to high presence of PAHs (Alomirah et al., 2011) while; in contrast, food with low fat content contains insignificant amount of PAHs (Marques et al., 2011).

iii) Cooking method (frying, grilling, roasting, boiling and smoking)

Among the method of cooking, heating i.e. grilling and smoking of food directly in contact with combustion gases is an important source of the contamination (Purcaro et al., 2013). According to Marques et al. (2011), the presence of PAHs in the cooked meat is greatly depending on the cooking method, being lower in oven baking and higher in wood fire grilled products. Furthermore, Perelló et al. (2009) has also revealed the levels of 16 PAHs in various foodstuffs that formed by cooking. Their finding stated that a considerable amount of PAHs has been detected in roasted samples.

\section{iv) Cooking temperature}

Severe temperature of cooking method such as grilling leads to formation of PAHs (Viegas et al., 2012). As the temperature rises, more PAHs are present (Farhadian et al., 2010). All compounds containing carbon and hydrogen can be optimal precursor of PAHs at high temperature $\left(500-700^{\circ} \mathrm{C}\right)$ (Purcaro et al., 2013). In fact, PAHs were involved in pyrolysis and pyrosynthesis, where PAHs compound are partially cracked into smaller, unstable molecules (pyrolysis), these fragments, mostly radicals, recombine to yield larger, relatively stable PAHs (pyrosynthesis)(Purcaro et al., 2013). PAHs can also formed at lower temperatures $\left(100-150^{\circ} \mathrm{C}\right)$ but they require a period on the geological time-scale and huge amount of alkylated PAHs were originated, as in the case of natural fossil fuel formation (Purcaro et al., 2013).

\section{v) Cooking duration/level of doneness}

Cooking duration was also contributed to the increase of PAHs level since the longer the cooking time, the higher the amount of PAHs (Purcaro et al., 2013). For example, level of heterocyclic amines compound which also has the same metabolizing pathways as PAHs, was also increased with increasing of cooking duration or level of doneness (Jinap et al., 2013).

vi) Type of fuel used or type of heat sources (electrical, gas, wood and charcoal)

Type of fuel used was also influenced the level of PAHs formed such as electric, gas, wood and charcoal. According to Purcaro et al. (2013), carbon burning produced a low level of PAHs than wood. Furthermore, Alomirah et al. (2011) has also revealed that grilling of meat in charcoal oven released substantial quantities of PAHs than meat that roasted in an electric oven.

vii) Proximity and direct contact with heat source Proximity is the distance from the heat source. In 
reference to Purcaro et al. (2013), the longer the distance, the lower the amount of PAHs in food. Charcoal grilling, as the high temperature process, can be applied to foods as an indirect or direct way. No carcinogenic PAHs will be detected in the grilled products if fat dripping onto the heat source is prevented. Therefore, avoiding direct contact of meat with the cooking flame or grilling at intense temperature can reduce the occurrence of PAHs during charcoal grilling (Farhadian et al., 2012).

\section{Bioaccessibility of Food Contaminant}

The term 'bioaccessibility' is one of the critical issues in order to accurately assess the exposure risk of contaminants from food which become available for intestinal absorption after digestion (Wang et al., 2011; $\mathrm{Hu}$ et al., 2013). Non-digested contaminants are not accessibly been absorbed in the human gastrointestinal tract. This unreleased contaminant which is bound to the food matrices will be excreted together with the faeces (Yu et al., 2011). Therefore, the concept of contaminant bioaccessibility has been applied by some researchers as the intestinal absorption rate is important to evaluate the human daily intake of contaminants (Yu et al., 2012).

Bioaccessibility can also be defined as the fraction of contaminant that mobilized from its matrix which is normally obtained via simulation of the human gastrointestinal digestion process (Yu et al., 2011; 2012). In fact, nutrition in foods is available for human absorption only after digestion (Intawongse and Dean, 2006). Bioaccessibility is easier to be carried out via in vitro experiments and it was commonly used as a substitute of bioavailability when estimating human exposure to food-borne contaminants (Yu et al., 2010). Indeed, bioaccessibility assessment is thus very desirable. Likewise, studies related to bioaccessibility were also been evaluated on heavy metals and soil (Tang et al., 2006; Yu et al., 2010; Maulvault et al., 2011). A study by Maulvault et al. (2011) on the bioaccessibility of mercury $(\mathrm{Hg})$ in raw and cooked black scabbard fish, as well as cadmium (Cd) and arsenic (As) in edible steamed and boiled crab tissues concluded that the $\mathrm{Cd}$ and As revealed high bioaccessibility rates in raw and cooked black scabbard fish with up to $100 \%$, whereas lower bioaccessibility of $\mathrm{Hg}$ was observed with up to $40 \%$.

Moreover, in a study on the bioaccessibility of diphenyl ethers (PBDEs) by Yu et al. (2010) in 13 types of foods including fish, meat, rice, flour and vegetables using in vitro digestion model, the bioaccessibility were ranged from $2.6 \%$ to $41.3 \%$. Besides, an assessment of PAHs bioaccessibility in soils from Beijing was also been done by Tang et al. (2006) using an in vitro test. Their studies reported that the bioaccessibility of PAHs in small intestine ranging from $9.2 \%$ to $60.5 \%$ was significantly higher than in stomach which ranging from $3.9 \%$ to $54.9 \%$.

An interest in the structural design of food-based delivery systems in encapsulating, protecting and releasing bioactive components which believed to give advantage to human health is increasing in these past few years. The functions of designing these delivery systems were to release the bioactive components at a specific location in the human gastrointestinal tract (GIT), and its release is triggered by external stimuli such as $\mathrm{pH}$, ionic strength and enzyme activity as well as to control the rate of bioactive release in the form of burst release or prolonged release (Hur et al., 2011). In vivo feeding methods which usually tested on animals or humans, provide the most accurate results; however, they are costly and time consuming. Hence, much effort has been devoted to the development of the in vitro method. In general, well-designed in vitro digestion models provide an alternative to animal and human models as well as serving a rapid, accurate and lesser time for screening foods or delivery system with different composition and structures (Coles et al., 2005; Hur et al., 2011).

\section{In vitro digestion model for bioaccessibility}

In vitro digestion model has been proposed as a tool to calculate the bioaccessibility of food-borne toxicants (Yu et al., 2010). The bioaccessible amount of a contaminant represent the maximal amount available in human gastrointestinal tract, and become available for absorption. This amount has been considered as the actual absorbed amount of toxicants in human exposure assessment, which was normally determined through multiplying total amount of a contaminant by the bioaccessibility (Yu et al., 2011). In vitro digestion model has been widely used in the purpose of studying the structural changes, digestibility, and release of food components under simulated gastrointestinal conditions (Hur et al., 2011; Omar et al., 2013). This model purports to simulate the digestion process in the gastrointestinal tract by applying physiological based conditions including gastric $\mathrm{pH}$, intestinal $\mathrm{pH}$, food constituents, residence time and particle size (Intawongse and Dean, 2006; Omar et al., 2013).

The most predominant food samples tested using in vitro digestion model were plants $(45 \%)$, meats $(18 \%)$, fish (9\%), dairy (9\%) and emulsion-based foods (9\%) (Hur et al., 2011; Omar et al., 2013). According to the surveys conducted in all the in vitro digestion models, the digestion temperature was set $37^{\circ} \mathrm{C}$ despite the variations types and concentrations of enzymes employed. Enzymes and other biological molecules commonly used in the model

Table 7. Enzymes Utilized in in vitro Digestion Model (Adapted from Hur et al., 2011)

\begin{tabular}{lll}
\hline Enzyme & Locations & Functions \\
\hline $\begin{array}{ll}\text { a. Amylase } \\
\text { b. Protease }\end{array}$ & mouth; stomach & convert starches to oligosaccharides and monosaccharides (glucose). \\
& stomach (pepsin) & breaking down proteins/peptides into smaller peptides and amino acids. \\
small intestine (trypsin and chymotrypsin) & convert triacylglycerols and diacylglycerols to monoacylglycerols and free \\
& stomach (gastric lipase) & fatty acids. \\
\hline
\end{tabular}


were digestive enzymes (pancreatin, pepsin, trypsin, chymotrypsin, peptidase, $\alpha$-amylase, and lipase), bile salts and mucin (Hur et al., 2011). However, the main enzymes utilized in in vitro digestion models were amylase (for starch digestion), protease (for protein digestion) and lipase (for lipid digestion) (Hur et al., 2011). The location and function of these enzymes is shown in Table 7.

An in vitro digestion model should fulfil the following criteria: i) the model has to represent physiology of human, ii) the last compartment in the model must be small intestine, as the absorption of compounds takes place mainly in the small intestine and, iii) the model also has to be applicable, robust and reproducible (Versantvoort et al., 2004; Omar et al., 2013). Moreover, this model offer the advantages of being simple, easy and fast, straightforward model, cost effective, provide accurate results within a short time, reduces the need to experimental animals, can investigate a large number of different samples and matrices as well as allowing replication and can provide insights that are not achievable in animal studies. These characteristics make it very useful tool for the human health risk assessment (Oomen et al., 2003; Omar et al., 2013).

\section{Conclusions}

In conclusion, in sum, to better evaluate the exposure of PAHs, it would be necessary to obtain more details information about barbecuing, consumption of smoked foods and occupational exposures. Unfortunately, there is still lacking of studies on the bioaccessibility of PAHs in food since most of the studies only been focused in soil. It is therefore we suggested that more studies should be conducted on the other meat and fish products to estimate the bioaccessibility of PAHs which available for human absorption. Since cancer risk associated with dietary intake of contaminants increased, health risk assessment through bioaccessibility is crucial as a tool to detect the presence of food contaminants in food. It is essential to decrease food contaminants accumulation especially in meat products as it gives large contribution in people's diet worldwide. Prevention, cure as well as control efforts toward the sources and factors contributing to the formation of contaminants can be applied through the health risk assessment.

\section{References}

Abou-Arab AAK, Abou-Donia MA, El-Dars FMSE, et al (2014). Detection of polycyclic aromatic hydrocarbons levels in Egyptian meat and milk after heat treatment by gas chromatography-mass spectrometry. Int J Curr Microbiol App Sci, 3, 294-305.

Afzaninawati SY, Zaleha MI, Shamsul AS (2013). Perceptions of Malaysian colorectal cancer patients regarding dietary intake: A qualitative exploration. Asian Pac J Cancer Prev, 14, 1151-54.

Akpambanga VOE, Purcaro G, Lajide L, et al (2009). Determination of polycyclic aromatic hydrocarbons (PAHs) in commonly consumed Nigerian smoked/grilled fish and meat. Food Addit Contam: A, 26, 1096-1103.

Alomirah H, Al-Zenki S, Al-Hooti S, et al (2011). Concentrations and dietary exposure to polycyclic aromatic hydrocarbons (PAHs) from grilled and smoked foods. Food Control, 22, 2028-35.

Al-Rashdan A, Helaleh MIH, Nisar A, et al (2010). Determination of the levels of polycyclic aromatic hydrocarbons toasted bread using gas chromatography mass spectrometry. Int $J$ of Anal Chem, doi:10.1155/2010/821216.

Anderson KE, Sinha R, Kulldorff M, et al (2002). Meat intake and cooking techniques: associations with pancreatic cancer. Mutat Res, 506-507, 225-31.

Chung SY, Yetella RR, Kim JS, et al (2011). Effects of grilling and roasting on the levels of polycyclic aromatic hydrocarbons in beef and pork. Food Chem, 129, 1420-26.

Coles LT, Moughan PJ, Darragh, AJ (2005). In vitro digestion and fermentation methods, including gas production techniques, as applied to nutritive evaluation of foods in the hindgut of humans and other simple-stomached animals. Anim Feed Sci Tech, 123-124, 421-44.

Danyi S, Brose F, Brasseur C, et al (2009). Analysis of EU priority polycyclic aromatic hydrocarbons in food supplements using high performance liquid chromatography coupled to an ultraviolet, diode array or fluorescence detector. Analytica Chimica Acta, 633, 293-9.

El-Badry, N (2010). Effect of household cooking methods and some food additives on polycyclic aromatic hydrocarbons (PAHs) formation in chicken meat. World Applied Sciences Journal, 9, 963-74.

Farhadian A, Jinap S, Faridah A, et al (2010). Determination of polycyclic aromatic hydrocarbon in grilled meat. Food Control, 21, 606-10.

Farhadian A, Jinap S, Faridah A, et al (2012). Effects of marinating on the formation of polycyclic aromatic hydrocarbons (benzo[a]pyrene, benzo[b]fluoranthene and fluoranthene) in grilled beef meat. Food Control, 28, 420-5.

Farhadian A, Jinap S, Hanifah HN, et al (2011). Effects of meat preheating and wrapping on the levels of polycyclic aromatic hydrocarbons in charcoal-grilled meat. Food Chem, 124, 141-6.

Gomes A, Roseiro C, Santos C (2009). Determination of polycyclic aromatic hydrocarbons profile in Portugese traditional dry fermented sausage. V Food Safety European Symposium, Berlin, Germany.

Hu J, Wu F, Wu S, et al (2013). Bioaccessibility, dietary exposure and human risk assessment of heavy metals from market vegetables in hong kong revealed with an in vitro gastrointestinal model. Chemosphere, 91, 455-61.

Hur SJ, Lim BO, Decker EA, et al (2011). In vitro human digestion models for food applications. Food Chem, 125, $1-12$.

Intawongse M, Dean JR (2006). In-vitro testing for assessing oral bioaccessibility of trace metals in soil and food samples. Trend in Analytical Chemistry, 25, 9.

International Agency for Research on Cancer (IARC) (1987). Overall evaluations of carcinogenicity. IARC monographs on the evaluation of carcinogenic risk of chemicals to humans. Lyon, France, 440, 7.

International Agency for Research on Cancer (IARC) (2004). Overall evaluations of carcinogenicity: An updating of IARC monographs. Lyon, France, 1-42, 7.

International Agency for Research on Cancer (IARC) (2010). Monographs on the evaluation of carcinogenic risk to humans. Some on-heterocyclic polycyclic aromatic hydrocarbons and some related exposures. Lyon, France, 92, 360-437.

Ishizaki A, Saito K, Hanioka N, et al (2010). Determination of polycyclic aromatic hydrocarbons in food samples by automated on-line in-tube solid-phase microextraction 
Polycyclic Aromatic Hydrocarbons and Bioaccessibility in Meat: a Tool for Assessing Human Cancer Risk

coupled with high-performance liquid chromatographyfluorescence detection. J Chromatogr A, 1217, 5555-63.

Jägerstad M, Skog K (2005). Genotoxicity of heat-processed foods. Mutat Res, 574, 156-72.

Jahurul MHA, Jinap S, Zaidul ISM, et al (2013). Determination of fluoranthene, benzo(b)fluoranthene and benzo(a)pyrene in meat and fish product and their intake by Malaysian. Food Bioscience, 1, 73-80.

Janoszka B, Warzecha L, Blaszczyk U, et al (2004). Organic compound formed in thermally treated high-protein food part i: polycyclic aromatic hydrocarbons. Acta Chromatographica, 14, 115-28.

Jarvis IWH, Dreiji K, Mattson A, et al (2014). Interactions between polycyclic aromatic hydrocarbons in complex mixtures and implications for cancer risk assessment. Toxicol, 321, 27-39.

Jinap S, Mohd-Mokhtar MS, Farhadian A, et al (2013). Effects of varying degrees of doneness on the formation of heterocyclic aromatic amines in chicken and beef satay. Meat Sci, 94, 202-7.

Jira W (2004). A GC/MS method for the determination of carcinogenic polycyclic aromatic hydrocarbons (PAHs) in smoked meat products and liquid smokes. Eur Food Res Technol, 218, 208-12.

Knightes CD, Peters CA (2006). Multisubstrate biodegradation kinetics for binary and complex mixtures of polycyclic aromatic hydrocarbons. Environ Toxicol Chem, 25, 1746-56.

Kulp KS, Fortson SL, Kniza MG, et al (2003). An in vitro model system to predict the bioaccessibility of heterocyclic amines from a cooked meat matrix. Food Chem Toxicol, 4, 1701- 10.

Marchand LL, Hankin JH, Pierce LM, et al (2002). Well-done red meat, metabolic phenotypes and colorectal cancer in Hawaii. Mutat Res, 506-507, 205-14.

Marques A, Lourenco HM, Nunes ML, et al (2011). New tools to assess toxicity, bioaccessibility and uptake of chemical contaminants in meat and seafood. Food Res Int, 44, 510-22.

Marť-Cid R, Llobet JM, Castell V, et al (2008). Evolution of the dietary exposure to polycyclic aromatic hydrocarbons in Catalonia, Spain. Food Chem Toxicol, 46, 3163-71.

Martorell I, Perelló G, Martî-Cid R, et al (2010). Polycyclic aromatic hydrocarbons (PAHs) in foods and estimated $\mathrm{PAH}$ intake by the population of Catalonia, Spain, temporal trend. Environ Int, 36, 424-32.

Maulvault AL, Raquel M, Cláudia A, et al (2011). Bioaccessibility of $\mathrm{Hg}, \mathrm{Cd}$ and $\mathrm{As}$ in cooked black scabbard fish and edible crab. Food Chem Toxicol, 49, 2808-15.

Omar NA, Praveena SM, Aris AZ, et al (2013). Bioavailability of heavy metals in rice using in vitro digestion model. Int Food Res J, 20, 2979-85.

Omwukeme VI, Obijiofor OC, Asomugha RN, et al (2015). impact of cooking methods on the levels of polycyclic aromatic hydrocarbons (PAHs) in chicken meat. IOSR J of Environ Sci, Toxicol and Food Technol, 9, 21-7.

Oomen AG, Rompelberg CJM, Bruil MA, et al (2003). Development of an in vitro digestion model to estimating the bioaccessibility of soil contaminants. Arch Environ Contam Toxicol, 44, 281-7.

Palm MNL, Derick C, Yeboah PO, et al (2011). Characterization of polycyclic aromatic hydrocarbon (PAHs) present in smoked fish from Ghana. Adv J Food Sci Technol, 3, 332-8.

Perelló G, Marť́-Cid R, Castell V, et al (2009). Concentrations of polybrominated diphenyl ethers, hexachlorobenzene and polycyclic aromatic hydrocarbons in various foodstuffs before and after cooking. Food Chem Toxicol, 47, 709-15.

Plaza-Bolanõs P, Frenich AG, Vidal JLM (2010). Polycyclic aromatic hydrocarbons in food and beverages. Analytical methods and trends. J Chromatogr A, 1217, 6303-26.
Purcaro G, Moret S, Conte LS (2013). Overview on polycyclic aromatic hydrocarbons: Occurrence, legislation and innovative determination in foods. Talanta, 105, 292-305.

Ramesh A, Walker SA, Hood DB, et al (2004). Bioavailability and risk assessment of orally ingested polycyclic aromatic hydrocarbons. Int $J$ Toxicol, 23, 301-33.

Reinik M, Tamme T, Roasto M, et al (2007). Polycyclic aromatic hydrocarbons (PAHs) in meat products and estimated PAH intake by children and the general population in Estonia. Food Addit Contam, 24, 429-37.

Roseiro LC, Gomes A, Santos C (2008). Polycyclic aromatic hydrocarbons profile in a Portugese traditional meat product. IAFP's Fourth European Symposium on Food Safety. Advancements in Food Safety, 19-21 November, Lisbon, Portugal. 47.

Silva BO, Adetunde OT, Oluseyi TO, et al (2011). Effects of the methods of smoking on the levels of PAH in some locally consumed fishes in Nigeria. African Journal of Food Science, 5, 284-391.

Šimko P (2002). Determination of polycyclic aromatic hydrocarbons in smoked meat products and smoke flavouring food additives. J Chromatogr B, 770, 3-18.

Sinha R, Chow WH, Kulldorff M, et al (1999). Well-done grilled red meat increases the risk of colorectal adenomas. Cancer Res, 59, 4320-24.

Sinha R, Rothman N, Salmon CP, et al (1998). Heterocyclic amine content in beef cooked by different methods to varying degrees of doneness and gravy made from meat drippings. Food Chem Toxicol, 36, 279-87.

Tang X, Tang L, Zhu Y, et al (2006). Assessment of the bioaccessibility of polycyclic aromatic hydrocarbons in soils from Beijing using an in vitro test. Environ Pollut, 140, 279-85.

Versantvoort C, Van de Kamp E, Rompelberg C (2004). Development and applicability of an in vitro digestion model in assessing the bioaccessibility of contaminants from food. Report no. 320102002. National Institute for Public Health and the Environment, Bilthoven, The Netherlands.

Viegas O, Novo P, Pinto E, et al (2012). Effect of charcoal types and grilling conditions on formation of heterocyclic aromatic amines (HAs) and polycyclic aromatic hydrocarbons (PAHs) in grilled muscle foods. Food Chem Toxicol, 50, 2128-34.

Wang H, Zhao Y, Man Y, et al (2011). Oral bioaccessibility and human risk assessment of organochlorine pesticides (OCPs) via fish consumption, using an in vitro gastrointestinal model. Food Chem, 127, 1673-79.

Yu Y, Chen L, Yang D, et al (2012). Polycyclic aromatic hydrocarbons in animal-based foods from Shanghai: bioaccessibility and dietary exposure. Food Addit Contam A, 29, 1465-74.

Yu Y, Huang N, Zhang X, et al (2011). Polybrominated diphenyl ethers in food and associated human daily intake assessment considering bioaccessibility measured by simulated gastrointestinal digestion. Chemosphere, 83, 152-60.

Yu Y, Li J, Zhang X, et al (2010). An assessment of the bioaccessibility of polybrominated diphenyl ethers in foods and the correlations of the bioaccessibility with nutrient contents. J Agric Food Chem, 58, 301-8. 